\title{
Risk Factors for Complications after Reconstructive Surgery for Sternal Wound Infection
}

\author{
Ichiro Hashimoto ${ }^{1}$, Mitsuru Takaku ${ }^{1}$, Shinji Matsuo ${ }^{1}$, Yoshiro Abe ${ }^{1}$, Hiroshi Harada ${ }^{2}$, \\ Hiroaki Nagae ${ }^{3}$, Yusuke Fujioka ${ }^{4}$, Kuniaki Anraku', Kiichi Inagawa ${ }^{6}$, Hideki Nakanishi ${ }^{1}$ \\ ${ }^{1}$ Department of Plastic and Reconstructive Surgery, The University of Tokushima Graduate School, Tokushima; ${ }^{2}$ Division of Plastic Surgery, \\ Kochi Health Sciences Center, Kochi; ${ }^{3}$ Department of Plastic and Reconstructive Surgery, Tokushima Red Cross Hospital, Komatsushima; \\ ${ }^{4}$ Department of Plastic and Reconstructive Surgery, Kurashiki Central Hospital, Kurashiki; ${ }^{5}$ Department of Plastic and Reconstructive \\ Surgery, Matsue Red Cross Hospital, Matsue; ${ }^{6}$ Department of Plastic and Reconstructive Surgery, Kawasaki Medical School, Kurashiki, Japan
}

Background Although the utility of flaps for the treatment of sternal wound infections following median sternotomy has been reported for 30 years, there have been few reports on the risk factors for complications after reconstruction. The objective of this investigation was to identify factors related to complications after the reconstruction of sternal wound infections.

Methods A retrospective analysis of 74 patients with reconstructive surgery after sternal wound infection over a 5-year period was performed. Clinical data including age, sex, body mass index (BMI), comorbidities, bacterial culture, previous cardiac surgery, wound depth, mortality rate, type of reconstructive procedure, and complication rate were collected.

Results The patients' BMI ranged from 15.2 to $33.6 \mathrm{~kg} / \mathrm{m}^{2}$ (mean, $23.1 \pm 3.74 \mathrm{~kg} / \mathrm{m}^{2}$ ). Wound closure complications after reconstructive surgery were observed in $36.5 \%$ of the cases. The mortality rate was $2.7 \%$. Diabetes mellitus significantly affected the rate of wound closure complications $(P=0.041)$. A significant difference in the number of complications was seen between Staphylococcus aureus (S. aureus) and coagulase-negative Staphylococci $(P=0.011)$. There was a correlation between harvesting of the internal thoracic artery and postoperative complications $(P=0.048)$. The complication rates of the pectoralis major flap, rectus abdominis flap, omentum flap, a combination of pectoralis major flap and rectus abdominis flap, and direct closure were $23.3 \%, 33.3 \%, 100 \%, 37.5 \%$, and $35.7 \%$, respectively.

Conclusions Diabetes mellitus, $S$. aureus, harvesting of the internal thoracic artery, and omentum flap were significant factors for complications after reconstruction. The omentum flap volume may be related to the complications associated with the omentum flap transfer in the present study.

Keywords Mediastinitis / Postoperative complications / Surgical flaps / Risk factors / Omentum
Correspondence: Ichiro Hashimoto Department of Plastic and Reconstructive Surgery, The University of Tokushima Graduate School, 2-18-15 Kuramoto, Tokushima 770-8503, Japan

Tel: $+81-88-633-7296$

Fax: +81-88-633-7297

E-mail: ichiro.h@tokushima-u.ac.jp

We would like to express our sincere gratitude to Dr. Hiroaki Mikasa, Support Center for Medical Education of The University of Tokushima, for help with the statistics; and Dr. Hisanao Aoki, Kurashiki Central Hospital; Dr. Kiyoko Hukui, Matsue Red Cross Hospital; Dr. Hirotaka Sugino, Tokushima Red Cross Hospital; and Dr. Yutaka Fukunaga, Kochi Health Sciences Center, for the data collection in each hospital.

No potential conflict of interest relevant to this article was reported. 


\section{INTRODUCTION}

Sternal wound infections, including sternal osteomyelitis and mediastinitis, following median sternotomy, continue to be a significant problem, with an incidence range of $0.4 \%$ to $3 \%$, and the associated mortality rate varies from $10 \%$ to $47 \%$ [1]. Various risk factors for developing sternal wound infections after cardiac surgery, such as bacterial etiology, diabetes mellitus, hypertension, previous operations including coronary artery bypass grafting and internal thoracic artery harvesting, have been reported [2-4]. The care of this devastating complication requires comprehensive approaches including infection control, rigorous debridement of damaged tissue, wound bed preparation, and dead space obliteration with vascularized flaps. Some types of flaps, such as pectoralis major muscle flaps, rectus abdominis muscle flaps, or omentum flaps, are reported to be effective reconstructive procedures. However, there have been few reports on the predictors of complications after sternal wound reconstruction $[2,5,6]$. The objective of this multicenter study was to identify risk factors for wound closure complications after surgical treatment for sternal wound infection.

\section{METHODS}

A retrospective study of 74 patients who underwent reconstructive treatments for sternal wound infections after thoracotomy for cardiac, vascular, or other surgery between January 2003 and March 2011 was conducted. The reconstructive treatments included flap transplantation and direct closure. Patients with a previous history of radiation therapy to the sternal region were excluded from this study. All patient data were collected from six hospitals (Tokushima University Hospital, Kochi Health Sciences Center, Tokushima Red Cross Hospital, Kurashiki Central Hospital, Matsue Red Cross Hospital, and Kawasaki Medical School Hospital). Basic data about age, sex, body mass index (BMI), comorbidities, bacterial culture before reconstructive treatment, previous cardiac surgery, harvesting of the internal thoracic artery for coronary artery bypass grafting (CABG), and prognosis were collected. The data collected about reconstruction included the depth of the sternal wound, reconstructive procedures, and complications after the reconstructive surgery. The depth of the sternal wound was categorized on the basis of Jones' classification: type 1 (superficial wound) skin and subcutaneous tissue dehiscence or exposure of sutured deep fascia; type 2 (depth on sternal bone) exposed bone, stable or unstable wired sternotomy; and type 3 (depth under sternal bone) exposed necrotic or fractured bone, exposure of the heart, or septicemia [2]. Wound closure complications after reconstructive surgery were defined as including dehiscence of the reconstructed wound due to wound infection, hematoma, and flap trouble. The factors that correlated with wound closure complications after sternal wound reconstruction were then analyzed. This study was approved by the institutional ethics committees of all the involved hospitals.

Statistical evaluation was performed with Fisher's exact test, McNemar's test, and logistic regression analysis using SPSS ver. 21 (Japan IBM, Tokyo, Japan). A P-value of less than 0.05 was considered significant. Data are presented as means \pm standard deviation.

\section{RESULTS}

The 74 patients included 47 male patients (63.5\%) and 27 female patients $(36.5 \%)$. The patients' age at the time of surgery ranged from 4 to 84 years (mean age, 67.8 years). The BMI ranged from 15.2 to $33.6 \mathrm{~kg} / \mathrm{m}^{2}$ (mean, $23.1 \pm 3.74 \mathrm{~kg} / \mathrm{m}^{2}$ ). Wound closure complications after reconstructive operations were observed in 27 patients (36.5\%). Two patients died after the reconstructive surgery, and the mortality rate in this study was $2.7 \%$.

Regarding the comorbidities, diabetes mellitus significantly affected the rate of wound closure complications (odds ratio, 3.25; $95 \%$ confidence interval, $1.05-10.05 ; \mathrm{P}=0.041$ ). The previous operations causing sternal wound infection were CABG in 49 patients (66.2\%), valve repair in 19 patients (25.7\%), aortic reconstruction in 5 patients $(6.8 \%)$, and other procedures including resection of mediastinal tumors in 6 patients (8.1\%) (Table 1 ). The wound closure complications after CABG, valve repair, aortic reconstruction, and other procedures were $32.7 \%, 31.6 \%$, $80 \%$, and $50 \%$, respectively. The odds ratio of complications after aortic reconstruction as compared to mediastinal tumor was

Table 1. Previous surgery and wound closure complications after reconstructive surgery

\begin{tabular}{|c|c|c|c|c|}
\hline Previous surgery & No. of cases $(\%)$ & No. of complications (\%) & Odds ratio (95\% confidence interval) & P-value \\
\hline Coronary artery bypass grafting & 49 (66.2) & $16 / 49(32.7)$ & $0.60(0.15-2.39)$ & 0.471 \\
\hline Valve repair & $19(25.7)$ & $6 / 19(31.6)$ & $0.63(0.12-7.52)$ & 0.548 \\
\hline Aortic reconstruction & $5(6.8)$ & $4 / 5(80)$ & $5.59(0.49-63.58)$ & 0.165 \\
\hline Mediastinal tumor & $6(8.1)$ & $3 / 6(50)$ & 1.0 (reference) & - \\
\hline
\end{tabular}


Table 2. Harvesting of the internal thoracic artery and wound closure complications after reconstructive surgery

\begin{tabular}{|lcc|}
\hline \multirow{2}{*}{$\begin{array}{l}\text { ITA harvesting } \\
\text { (No. of cases, \%) }\end{array}$} & \multicolumn{2}{c|}{ Wound closure complications } \\
\cline { 2 - 3 } & Yes $(\%)$ & No (\%) \\
\hline Yes $(41 / 74,55.4)$ & $12 / 41(29.3)$ & $29 / 41(70.7)$ \\
No $(33 / 74,44.6)$ & $15 / 33(45.5)$ & $18 / 33(54.5)$ \\
\hline $\begin{array}{l}\text { The P-value calculated using McNemar's test is } 0.048 . \\
\text { ITA, internal thoracic artery. }\end{array}$
\end{tabular}

Table 3. Bacterial pathogens before reconstruction and wound closure complications after reconstruction

\begin{tabular}{|lcc|}
\hline Bacterial pathogen & No. of cases (\%) & No. of complications (\%) \\
\hline Staphylococcus aureus & $38(56.7)$ & $18 / 38(47.4)$ \\
$\begin{array}{l}\text { Coagulase-negative } \\
\text { Staphylococci }\end{array}$ & $21(31.3)$ & $3 / 21(14.3)$ \\
Others & $3(4.5)$ & $1 / 3(33.3)$ \\
Negative & $5(7.5)$ & $0 / 5(0)$
\end{tabular}

There was no data about bacterial culture in 7 cases. The P-value in the comparison of complications between Staphylococcus aureus and coagulase-negative Staphylococci calculated using Fisher's exact test is 0.011 .

high but not significant. A larger number of cases compared to that considered in the present study may be needed for further explanation of the effect of the previous operations to the complications. Harvesting of the internal thoracic artery for CABG was performed in 41 (55.4\%) patients (Table 2); of these, 12 (29.3\%) patients developed wound dehiscence after reconstruction. In 33 patients without harvesting of the internal thoracic artery, wound dehiscence occurred in 15 (45.5\%). There was a correlation between harvesting of the internal thoracic artery and postoperative complications $(\mathrm{P}=0.048)$.

The bacterial pathogens detected before the reconstruction were Staphylococcus aureus (S. aureus) in 38 patients (56.7\%) and coagulase-negative Staphylococci (CNS) in 21 patients (31.3\%) (Table 3). Complication rates of the patients having $S$. aureus and CNS were $47.4 \%$ and $14.3 \%$, respectively; patients with $S$. aureus had a significantly higher rate $(\mathrm{P}=0.011)$.

In terms of the depth of the sternal wound, 7 patients $(9.5 \%)$ had type 1,17 (23\%) had type 2, and $50(67.5 \%)$ had type 3 (Table 4 ). The number of type 1 , type 2 , and type 3 patients with wound closure complications was 4 (57.1\%), 4 (23.5\%), and 19 (38\%), respectively. There was no correlation between sternal wound depth and postoperative complications $(\mathrm{P}=0.278)$.

The number of reconstructive procedures used with each type of wound depth and the number of patients having wound closure complications with each procedure are shown in Table 5. In the case of type 3 wound depth, the pectoralis major flap, omentum flap, a combination of the pectoralis major and rectus
Table 4. Wound depth and wound closure complications after reconstructive surgery

\begin{tabular}{|lcr|}
\hline \multirow{2}{*}{$\begin{array}{c}\text { Depth of wound } \\
\text { (No. of cases, } \%)\end{array}$} & \multicolumn{2}{c|}{ Wound closure complication } \\
\cline { 2 - 3 } & \multicolumn{1}{c|}{ Yes $(\%)$} & No $(\%)$ \\
\hline Type $1(7,9.5)$ & $4 / 7(57.1)$ & $3 / 7(42.9)$ \\
Type 2 $(17,23)$ & $4 / 17(23.5)$ & $13 / 17(76.5)$ \\
Type 3 $(50,67.5)$ & $19 / 50(38.0)$ & $31 / 50(62.0)$ \\
\hline The P-value calculated using Fisher's exact test is 0.278. & \\
\hline
\end{tabular}

Table 5. Reconstructive procedures, wound depth, and wound closure complications after reconstructive surgery

\begin{tabular}{|c|c|c|c|c|}
\hline \multirow{2}{*}{$\begin{array}{l}\text { Reconstructive } \\
\text { procedures } \\
\text { (No. of cases) }\end{array}$} & Type & pe & Туре 3 & \multirow{2}{*}{$\begin{array}{c}\text { Total no. of } \\
\text { complications }(\%)\end{array}$} \\
\hline & \multicolumn{3}{|c|}{ (recurrence/total cases) } & \\
\hline PM flap (30) & 0 & $0 / 9$ & $7 / 21$ & $7 / 30(23.3)$ \\
\hline Omentum flap (10) & $2 / 2$ & $2 / 2$ & $6 / 6$ & $10 / 10(100.0)$ \\
\hline $\begin{array}{l}\text { Combination of PM and } \\
\text { RA (8) }\end{array}$ & 0 & $1 / 1$ & $2 / 7$ & 3/8 (37.5) \\
\hline RA flap (6) & $1 / 1$ & 0 & $1 / 5$ & $2 / 6$ \\
\hline Direct closure (14) & $1 / 3$ & $1 / 4$ & $3 / 7$ & $5 / 14(35.7)$ \\
\hline Others (6) & $0 / 1$ & $0 / 1$ & $0 / 4$ & $0 / 6(0)$ \\
\hline \multicolumn{5}{|c|}{$\begin{array}{l}\text { Others included skin graft in } 2 \text { patients (Type } 1 \text { and 2), latissimus dorsi muscle } \\
\text { flap in } 2 \text { patients, local flap in } 1 \text { patient, and combination of the pectoralis major } \\
\text { and omentum flaps in } 1 \text { patient. The P-value calculated using Fisher's exact test } \\
\text { comparing recurrence by reconstructive procedure is } 0.0004 \text {. } \\
\text { PM, pectoralis major; RA, rectus abdominis. }\end{array}$} \\
\hline
\end{tabular}

abdominis flaps, rectus abdominis flap, and direct closure were selected in $21,6,7,5$, and 7 patients, respectively. The complication rates of the pectoralis major flap, omentum flap, the combination of the pectoralis major and rectus abdominis flaps, rectus abdominis flap, and direct closure were $23.3 \%, 100 \%, 37.5 \%$, $33.3 \%$, and $35.7 \%$, respectively. Other procedures included skin graft in 2 patients, latissimus dorsi muscle flap in 2 patients, local flap in 1 patient, and the combination of the pectoralis major and omentum flaps in 1 patient. The complication rate of the other procedures was $0 \%$, although the number of these cases was small. There was a significant correlation between the reconstructive procedure and the complication rate $(\mathrm{P}=0.0004)$. The patient who underwent reconstruction with the combination of the pectoralis major and omentum flaps had no wound closure complication.

\section{DISCUSSION}

Surgical treatment for complex sternal wounds has varied from debridement with simple drainage to debridement with autologous vascularized flap closure. Although various risk factors for developing sternal wound infections after cardiac surgery have been reported [2-4], there have been few reports on the 
predictors of complications after sternal wound reconstruction. In these reports, smoking, hypertension, diabetes mellitus, congestive heart failure, renal insufficiency, and intra-aortic balloon pump were listed as risk factors related to increased complications after reconstruction $[2,5,6]$. Since patients who undergo cardiac operations generally have poor general status, the recurrence of sternal wound infections can lead to a life-threatening condition such as sepsis or multiple organ failure.

In the present study, diabetes mellitus was a risk factor for wound closure complications. Elevated blood glucose levels may impair wound healing, and the continuous use of intravenous insulin has been shown to significantly reduce the incidence of sternal wound infection in diabetic patients [7]. Strict control of the diabetic patient's condition is needed to prevent complications after reconstruction surgery. Harvesting of the internal thoracic artery was a significant factor related to complications in the present study, and some reports have identified it as a risk factor for sternal infection $[3,8]$. The mechanism is related to devascularization of the wound around the sternal bone, which may delay proper wound healing after harvesting of the internal thoracic artery.

The most common causal pathogens for sternal wound infections are Staphylococcus epidermis (CNS) and $S$. aureus, both from the normal skin flora [9-11]. CNS infections generally have a late and insidious onset and are often associated with less severe symptoms of mediastinitis as compared to mediastinitis caused by other bacteria [12]. S. aureus may have a more aggressive nature and demonstrate more classical signs of infection. No difference in mortality has been reported between sternal infections caused by CNS and S. aureus [9]. The reason for the significant difference in the number of complications observed between CNS and $S$. aureus in the present study is not clear. A higher rate of positive blood cultures for $S$. aureus as compared to CNS has been reported in patients with sternal infections [9]. A possible reason for more complications after $S$. aureus infection is the presence of the pathogen in the blood after the reconstruction.

In the present study, the classification of sternal wound infections was adopted from a previous report [2]. Type 1 is a wound on the sternal bone that is not exposed. Type 2 is a wound with exposure of the sternal bone that is stable or unstable. In this type, it is important but not easy to check the viability and infection of the bone. When the wound is not infected and the bone is vascularized, rewiring and direct closure of the skin can be performed. Type 3 is complete sternal disruption and suppurative mediastinitis. Patients with type 3 in the present study accounted for $67.5 \%$ of the cases; they had a reconstruction procedure with muscle flaps or an omentum flap in $78 \%$ of the cases.
There was no significant correlation between wound depth and wound closure complications, because suitable procedures can be selected for each wound depth. However, one reason why type 2 had a relatively high complication rate may be that the viability of these wounds is most difficult to judge [2].

The pectoralis major flap was the most commonly selected procedure for reconstruction and had the lowest complication rate in the present study. The pectoralis major flap is reported to be the most favored method for the reconstruction of sternal wound infections $[2,11,13]$. However, the inferior or deep part of the sternal bone is sometimes out of reach of the pectoralis major flap. Some approaches to increase the width of the muscle to achieve a wider reach have been presented $[14,15]$. Furthermore, a combination of the pectoralis major and rectus abdominis flaps has been reported for long and deep defects $[16,17]$ because the pectoralis major flap and the rectus abdominis flap are suitable for superior and inferior sternal wound defects, respectively [18]. An unexpected finding of the present study was that the wound closure complication rate of omentum flaps was considerably higher than the average (36.5\%). The omentum flap transfer is reported to be a useful procedure for the reconstruction of sternal wound infections [19,20], although no significant difference in prognosis has been shown between the omentum flap and the muscle flap [20,21]. The weight of the omentum varies from 170 to $1,400 \mathrm{~g}$ and is representative of the visceral adipose tissue mass [22]. The mean BMI (24.3 \pm 4.2 $\left.\mathrm{kg} / \mathrm{m}^{2}\right)$ in patients who underwent omentum flaps in the present study was not high. The high complication rate after the omentum flap may be related to the inadequate volume of the omentum for the defect size. In order to add tissue volume to the omentum flap, a combination use of omentum and muscle flaps is recommended for sternal wounds with wide defects [2325]. Another factor that can increase the complication rate after an omentum flap is the effects on the patients' respiratory efforts because an additional body cavity has to be opened to harvest the flap. In the present study, details on omentum flap transfer such as the volume or the weight of the flap, features of wound condition, timing of transplantation, and the harvesting procedure were not investigated. A further study is required to delineate the safe use of the omentum flap. There are many types of defects on and under the sternal bone. Estimation of defect size before debridement and selection of a suitable flap for the defect and the general condition is important.

\section{REFERENCES}

1. El Oakley RM, Wright JE. Postoperative mediastinitis: classification and management. Ann Thorac Surg 1996;61: 
1030-6.

2. Jones G, Jurkiewicz MJ, Bostwick J, et al. Management of the infected median sternotomy wound with muscle flaps. The Emory 20-year experience. Ann Surg 1997;225:766-76.

3. Lu JC, Grayson AD, Jha P, et al. Risk factors for sternal wound infection and mid-term survival following coronary artery bypass surgery. Eur J Cardiothorac Surg 2003;23:943-9.

4. Morisaki A, Hosono M, Sasaki Y, et al. Evaluation of risk factors for hospital mortality and current treatment for poststernotomy mediastinitis. Gen Thorac Cardiovasc Surg 2011;59: 261-7.

5. Zahiri HR, Lumpkins K, Kelishadi SS, et al. Significant predictors of complications after sternal wound reconstruction: a 21-year experience. Ann Plast Surg 2012;69:439-41.

6. Kaye AE, Kaye AJ, Pahk B, et al. Sternal wound reconstruction: management in different cardiac populations. Ann Plast Surg 2010;64:658-66.

7. Furnary AP, Zerr KJ, Grunkemeier GL, et al. Continuous intravenous insulin infusion reduces the incidence of deep sternal wound infection in diabetic patients after cardiac surgical procedures. Ann Thorac Surg 1999;67:352-60.

8. Loop FD, Lytle BW, Cosgrove DM, et al. J. Maxwell Chamberlain memorial paper. Sternal wound complications after isolated coronary artery bypass grafting: early and late mortality, morbidity, and cost of care. Ann Thorac Surg 1990;49: 179-86.

9. Gardlund B, Bitkover CY, Vaage J. Postoperative mediastinitis in cardiac surgery - microbiology and pathogenesis. Eur J Cardiothorac Surg 2002;21:825-30.

10. Baskett RJ, MacDougall CE, Ross DB. Is mediastinitis a preventable complication? A 10-year review. Ann Thorac Surg 1999;67:462-5.

11. Lindsey JT. A retrospective analysis of 48 infected sternal wound closures: delayed closure decreases wound complications. Plast Reconstr Surg 2002;109:1882-5.

12. Tegnell A, Aren C, Ohman L. Coagulase-negative staphylococci and sternal infections after cardiac operation. Ann Thorac Surg 2000;69:1104-9.

13. Ascherman JA, Patel SM, Malhotra SM, et al. Management of sternal wounds with bilateral pectoralis major myocutaneous advancement flaps in 114 consecutively treated patients: refinements in technique and outcomes analysis. Plast Reconstr Surg 2004;114:676-83.

14. Li EN, Goldberg NH, Slezak S, et al. Split pectoralis major flaps for mediastinal wound coverage: a 12-year experience. Ann Plast Surg 2004;53:334-7.

15. Spiess AM, Balakrishnan C, Gursel E. Fascial release of the pectoralis major: a technique used in pectoralis major muscle closure of the mediastinum in cases of mediastinitis. Plast Reconstr Surg 2007;119:573-7.

16. Solomon MP, Granick MS. Bipedicle muscle flaps in sternal wound repair. Plast Reconstr Surg 1998;101:356-60.

17. Greig AV, Geh JL, Khanduja V, et al. Choice of flap for the management of deep sternal wound infection: an anatomical classification. J Plast Reconstr Aesthet Surg 2007;60:372-8.

18. Davison SP, Clemens MW, Armstrong D, et al. Sternotomy wounds: rectus flap versus modified pectoral reconstruction. Plast Reconstr Surg 2007;120:929-34.

19. Krabatsch T, Fleck E, Hetzer R. Treating poststernotomy mediastinitis by transposition of the greater omentum: late angiographic findings. J Card Surg 1995; 10:46-51.

20. Lopez-Monjardin H, de-la-Pena-Salcedo A, MendozaMunoz M, et al. Omentum flap versus pectoralis major flap in the treatment of mediastinitis. Plast Reconstr Surg 1998; 101:1481-5.

21. Atkins BZ, Onaitis MW, Hutcheson KA, et al. Does method of sternal repair influence long-term outcome of postoperative mediastinitis? Am J Surg 2011;202:565-7.

22. Arner P, Andersson DP, Thorne A, et al. Variations in the size of the major omentum are primarily determined by fat cell number. J Clin Endocrinol Metab 2013;98:E897-901.

23. Stump A, Bedri M, Goldberg NH, et al. Omental transposition flap for sternal wound reconstruction in diabetic patients. Ann Plast Surg 2010;65:206-10.

24. Kobayashi T, Mikamo A, Kurazumi H, et al. Secondary omental and pectoralis major double flap reconstruction following aggressive sternectomy for deep sternal wound infections after cardiac surgery. J Cardiothorac Surg 2011;6:56.

25. Izaddoost $S$, Withers EH. Sternal reconstruction with omental and pectoralis flaps: a review of 415 consecutive cases. Ann Plast Surg 2012;69:296-300. 